\title{
Gender aspects in urban human settlement planning
}

\author{
Rangajeewa Ratnayake
}

\begin{abstract}
The main trust of planners is to create inclusive human settlements. Inclusive planning approach recognizes the needs and aspirations of all social groups and thereby creates a livable environment for all social groups. Women comprise the majority of the population in almost all the societies in the world. Even though women constitute the majority of the total population, gender specific considerations have not been effectively addressed in land use planning and development planning in most of the developing countries and Sri Lanka is no exception. Therefore it is high time to address gender considerations in land use planning. One may not agree with the view points expressed in this article. However the objective of this article is to encourage debate among planners on the view points expressed in this article.
\end{abstract}

This article discusses that gender studies are concerned needs of both women and men. However urban and rural womens' needs are different and complex than the needs of men. Women daily activities, transport needs are different those of men. This article discusses the implications of mono land use practices on women by not integrating shopping areas, open spaces and nursery areas in housing neighborhoods. Attention is also paid as to how the safety in the built environment and availability of open spaces affect especially the social mobility of women. This article highlights gender and poverty and planning problems of families headed by women in Sri Lanka.

If women occupy decision making positions in society, they can also address womens' aspirations. This article discusses the status of women in public office in Sri Lanka and trend patterns of women in mainstream politics in Sri Lanka.

The latter part of this article discusses the possible Gender Planning Frameworks that can be used in human settlement process.

\section{Introduction}

In promoting social equity in human settlement planning, the advancement of women and improving their living environment is an important aspect of consideration. In Sri Lanka, women comprise 50.54 per cent of the population. (Census: 2001) Since "planning is for people" reasonable attention should be focused on the needs of women. However, prospects and problems those women face in cities and towns have not been effectively addressed when they work and live in human settlements. One of the major aims in urban planning is to create inclusive cities. Inclusive cities where the needs of men and women are treated equally without discrimination. If women do not enjoyequal benefits when compared to men and have thus become a less privileged group, then there is gender discrimination. Is it necessary to plan specially or differently for women? One could argue that women's urban needs and the way they use the city are different from men.

The term human settlement means not only providing shelter and secure land tenure but it encompasses the immediate needs of individuals in water, sanitation, social and physical infrastructure, employment opportunities. Each and every need listed above enables individuals to live and work in dignity with security.

Prior to discussing gender issues in planning it is worthy to understand the meaning of the term gender. The clear understanding of the concept will help create awareness on gender specific issues in human settlements planning and create guidance to formulate human settlement plans with a gender perspective.

\section{What is Gender?}

\section{Difference between Sex and Gender}

Sex refers to the biological characteristics that categorize someone as either female or male. Biological differences are the starting point of gender different roles between men and women. However biological differences cannot explain broader gender inequalities in our society. For instance biological differences cannot explain why women have less access to power, resources, and have lower status than men. 
Gender refers to the socially constructed ideas and practices of what it is to be male or female.(IDS: Bridge, 2000) It is society that socializes its members to perform two different roles. Women are socialized to be feminine and men to be masculine. This results in men to be dominant, leading and aggressive in role-playing, while women play a moresubmissive role in society. Likewise gender based hierarchical power relations are created due to socially or culturally constructed ideologies. This means gender inequality is an outcome of the social processes.

\section{Women and Development Discourse}

There are two main approaches to explain womens' subordinate position in society and strategies to achieve gender sensitive inclusive cities. The WID (or Women In Development) approach evolved in the 1970s, emphasizes the need to integrate women into the development process. It marked that women should be integrated into the development process as active agents if efficient and effective development is to be achieved. Women subordination was seen in terms of their exclusion from the market place, and limited access to control over resources. WID approach suggested programmes to address women practical needs, for example, creating income generating opportunities, improving access to credit, and to education, providing adequate living conditions, health care, food provision, access to safe water, and sanitation.

The other approach GAD (or Gender and Development) emerged due to the lack of progress of strategies associated with WID approach. GAD emphasizes that gender is some thing socially created and if it is so, it should be socially deconstructed by challenging existing gender roles and relations. To do it women should not hesitate to do jobs that are considered as male's jobs. For instance women should participate in technical professions, community organization roles, and active politics.

GAD approach focuses on strategies aiming to meet some Practical Gender Needs (PGNs) such as ensuring access to income -earning opportunities, improving access to credit, and to education and more Strategic Gender Needs (SGNs) such as participation in decision making processes and involve involvement in non traditional gender roles.

\section{Some Gender Specific Problems that need to be addressed in Human Settlement Planning Gender Based Poverty}

It has been found that women earn less than men in the developing world. Gender disaggregated data is not available at present to substantiate the feminization of poverty in Sri Lanka. However the only gender disaggregated data available to analyze gender-based poverty is the mean income of "income receivers". According to table 01, the percentage of female income receivers has increased from 31.4\% to $37.2 \%$ from 1996 to 2002 but the gender gap in mean income has widened in all planning sectors in Sri Lanka. It also shows that the male / female ratio has increased from 1.63 to 1.79 overall; from 1.68 to 1.87 in urban sector and 1.68. to 1.78 in rural sector.

Table 01: Income Receivers- Mean Income

\begin{tabular}{|c|c|c|c|c|c|c|c|c|}
\hline \multicolumn{5}{|c|}{$1996-1997$} & \multicolumn{4}{|c|}{2002} \\
\hline & \multirow{2}{*}{$\begin{array}{l}\% \\
\begin{array}{l}\text { Female } \\
\text { receivers } \\
\text { of Total }\end{array}\end{array}$} & \multicolumn{3}{|c|}{ Mean Income (Rs.) } & \multirow{2}{*}{\begin{tabular}{l|}
$\%$ \\
$\begin{array}{l}\text { Female } \\
\text { receivers } \\
\text { of Total }\end{array}$ \\
\end{tabular}} & \multicolumn{3}{|c|}{ Mean Income (Rs.) } \\
\hline & & Male & Female & $\begin{array}{l}\text { Male/Female } \\
\text { Ratio }\end{array}$ & & Male & Female & $\begin{array}{l}\text { Male/Female } \\
\text { Ratio }\end{array}$ \\
\hline Total & 31.4 & 6,556 & 4,025 & 1.63 & 37.2 & 8,476 & 4,722 & 1.79 \\
\hline Urban & 33.9 & 10,955 & 6.521 & 1.68 & 38.7 & 14,182 & 7,570 & 1.87 \\
\hline Rural & 29.8 & 6,082 & 3,810 & 1.60 & 36.4 & 7,803 & 4,369 & 1.78 \\
\hline Estate & 47.9 & 2,922 & 2,208 & 1.32 & 45.8 & 4,190 & 2,897 & 1.44 \\
\hline
\end{tabular}

Source: Report on Consumer Finance and SocioEconomic Survey, 1996/1997 and Central ADB Household Income and Expenditure Survey, 2002 (Exclude North and East), Department of Census and Statistics.

\section{The Gender Dimension on Access to Land Tenure, Housing and Basic Urban Services}

Women are often deprived right to claim for immovable properties; land, housing specially in rural areas. This is basically due to the patriarchy and gender stereotype dogmatic beliefs and that discourage parents to give immovable properties when they get married. This will make an effect on the status of women and on the economic potential of their families.

Human settlement should be conducive for human habitation. Most of these settlements lack the standard housing condition, and the settlers are deprived of basic services. There are number of spatial entities which can highlight that urban and rural poor who live in settlements are not favorable for human habitation. These conditions not only affect female but all the family members as well. Therefore any investment on housing related services will have multiple results. Basic services like water supply programme will reduce the burden on women because most of the time it is women who draw water for the family. This will give women time to involve in other productive economic activity. Health related programme designed especially for women will affect the health condition of the family as a whole.

In the field of the Housing sector in Sri Lanka, there is ample evidence of women organising themselves to improve their physical surroundings. The Millennium Housing Development Programme (NHDA), Urban Settlement Improvement Project, Sustainable Cities Programme ( UNDP/UN-Habitat) and many UN and CIDA funded, Orangi pilot project in Pakistan cite examples of a range of low-income urban women's organisational activities around health issues, child care, water, waste recycling, and self-help housing, indicating a commitment to urban life unmatched by official support or encouragement. 


\section{Gender and Transport Facilities}

Women and men have distinct transport requirements. Yet transport planning often disregards women's priorities because of a focus on mobility of the formal sector worker's journey and itinerary. Almost all the urban and rural areas, as far as the public transport system is concerned, state provide more trips during peak hours than off- peak hours considering the reduction of transport cost.(Habitat Debate, 2005) Women's travel needs frequently require transport outside of peak hours and to alternative destinations from those of men due to their dual role. It should be noted here that it is not only the priorities of women that are overlooked by conventional transport planning, but also those of men outside of centrally located, formal sector employment. Due to the forces of urbanization women have dual careers. They work in the formal and informal economy and women also have to bear most domestic and community management responsibilities. For example, women are most likely to be the ones looking after young children, elderly or sick relatives, and visiting schools and clinics. Most women depend on public transport and walking than on private cars or other vehicles. Yet conditions of travel on public transport are often questionable. Affordable transport systems circumvent critical destinations; they are overcrowded and sometimes dangerous and are often unreliable and irregular. It is also noted that women cannot compete with men just to get into to crowded buses. It is worse when women travel in the night after work. This hinders women in their domestic and caring responsibilities, impedes their productivity and even threatens their safety.

Some women planners argue that women find themselves marginalized in the city. They call the "Gender nature of urban space" can be seen in the way urban space restrict womens' mobility. (Karp, Stone \& Yoels, 1991:153) for the reasons given herein, lack of public transport facilities will restrict women's pattern of movement in urban.

\section{Planning Problems of Families headed by Women}

With the urbanization process, the share of families headed by women is rising in Sri Lanka. The studies have showed that the percentage of such families has increased from 16\% to 19\% from 1981 to 1995 in Sri Lanka.(Thiruchandran Selvy: 1999)A micro study carried out in two villages namely Nadeegama and Diyagama in Matara District in Sri Lanka indicate that families headed by women account for a significant proportion (22-\%25\%) of the total households.(Weerasinghe:2000) A growing phenomenon is an increase in the number of women-maintained families' especially due domestic conflicts and the on going ethnic conflicts. Official statistics may not be available to indicate a comprehensive picture of above situation in Sri Lanka, but the micro studies carried out in the Eastern Province indicate that 10,000 to 15000 women have become widowed from 1995-2000. In these households, the majority of the families are below the poverty line. .(Thiruchandran Selvy: 1999) They are disproportionately affected by unsatisfactory housing, environmental degradation, the failure of local government, city officials or the private sector to respond to their priorities in relation to infrastructure, services, and social exclusion by relatives and alienation of properties of their husbands.

Women usually earn less than men but this is particularly likely if they are among the growing number of households headed by women both in the industrialised countries of the West and in the developing world. It is estimated that globally one third of households are now de facto women-headed, with the percentage often being higher in urban areas. (Beall :1996) Households which are headed or maintained by women are likely to be poorer than those headed by men in Sri Lanka.(Economic Review 1995 August, 2000 December - November) Women from these households engage in specific livelihoods for income-generation and face special problems in relation to child rearing and when engaging in community activities.

\section{Gender and City Safety}

Womens' mobility is also restricted at night due to fear of attack, mugging, robbery and sexual harassments. A study in Woolwich, for example showed that $65 \%$ of women were afraid of going out at night for fear of attack. Another study in Edinburgh showed how women were dissatisfied with the town centre due to dirty and poorly lit streets, inadequate bus services and a fear of sexual harassments. (Worpole, 1992:65)

One of the major characteristics of third world urbanization process is that these countries are dominated by one or two major cities. These cities experience inappropriate densities and daily exodus commuting populations which make anonymity in cities. Some studies have shown how urban conditions which create anonymity can also create violence. (Karp, Stone, \& Yoels, 1991) This can create danger and harm for those who are physically vulnerable. Therefore urban space will not have the same excitement as it does for men. This is why the women planners argue that cities are historically built and run by men. (Greed, 2000) As other affairs of life women have been marginalized in the process of planning of urban space. For example Richter (1982) showed that little reference made to women's role in building American cities, especially where the physical development of urban fabric was involved.

\section{Gender and Recreation}

Many planning fields and sport complexes / pavilions have been provided in urban areas. However the provision of generalized open spaces and sport complexes for all 
the type of social groups has been questioned for many years. (Jacob,1964) It is apparent that most of the play areas are occupied for games involved in lots of movements eg. Cricket in Sri Lanka. Women with children tend to think that these spaces are not safe for women with young children. Thus public sport facilities to a greater extent are used by men. A Sports pavillion is usually considered as a male's territory.

To solve some of these problems some women planners suggest the provision of clearly defined different open spaces with alternative uses and more supervision (Greed:2000)

\section{Gender and Access to Decision Making Positions}

Women constitute a significant proportion, sometimes a majority, of urban populations. Getting women themselves into the mainstream of public office and the bureaucracy is a vital part of engendering urban governance. The presence of women in public office is assumed to guarantee that the interests of other women will be represented. The presence of women in public does not guarantee that womens' interests will be represented. Political beliefs, ideology, race and class all intersect, and sometimes compete, with the claims of gender, thus complicating the relationship between women in power and the representation of women's interests. However, this complexity does not diminish the critical importance and the symbolic and practical value of raising the profile of women in public office.

In the case of Sri Lanka, womens' participation in politics has not been at a satisfactory level. Statistics available may not present a complete picture, but present a dismal picture.. The number of women in parliament has remained less than 6\% - unchanged since 1931. At the 2000 parliamentary election, only nine were women (4\%) out of the 225 parliament members and 13 women MPs ( $5 \%$ ) were elected at the last general election in 2004. However the number of women candidates who contested for the General Elections has increased since 1931 where only one women candidate contested. This figure has increased to 55 at the 1994 parliamentary election. There were 117 women candidates out of $4768(2.4 \%)$ total candidates at the 2000 parliamentary election, and showing a considerable leap up, 300 women contested out of 5067 (5.9\%) total candidates at the 2004 general election. At provincial level, at the 1999 PC election, eleven women councilors were elected $(3 \%)$ in six of the councils. This was out of a total number of 378 council members.

The representation of women in local government bodies is worse. At the March 1997 LG election, 73 women (1.9\%) elected out of 3793 persons holding office. There were nine out of $261 \mathrm{MC}$ councilors (3.4\%), nine out of UC councilors (2.6\%) 55 out of 3,192 PS members (1.7\%) There were no women Mayors of 16 Municipal Councils, Chairpersons of 36 Urban Councils and chairpersons of Pradeshiya Sabhas in Sri Lanka according to the LG election result in 2002.

While Sri Lanka lags behind where women political participation is concerned, its one time colonizer, United Kingdom has produced 120 MPs at the 1997 election. India has also shown a progress by changing its electoral laws few years ago to ensure that at least $33 \%$ of those elected at Local Government level (Panchayat) were women. This step has been taken to empower the women in domain of decision making.

Studies have been conducted in Sri Lanka to understand why women do not enter politics. (Leitan \& Gunasekara, 1998) Some of the obstacles identified by the responders were gender specific and other apply to both sexes. The most common reasons are fear of violence, the slander "character assassination" and verbal abuse, inability to find time to engage in politics, objected to them getting involved in politics, lack of financial resources, political victimization that women face, and political parties are reluctant to nominate women.

Reservation and other affirmative actions will no doubt ensure the representation of more women in national, provincial and local level political organizations. However the key factor is whether there are institutional structures and linkages to ensure that the specific interests of women are represented by local councils, and whether councilors have transparent, open channels of communication and mechanisms for consultation with their constituencies.

\section{Identification of Gender Planning Framework for Human Settlement Planning}

Many gender planning frameworks have been developed based on different approaches. Caroline Moser (1993) developed a gender planning framework consisting Gender planning tools (involves gender analysis, gender need assessment) Gender planning procedures (involves diagnosis of gender related problems, formation of gender objectives, gender based consultation and participation, identification of strategies, and procedure for monitoring and evaluation) and components for gender planning practice (involves institutionalize the strategy, and capacity building )

linstitutional strategies basically focus on policy level changes. It means new policies have to be introduced such as reservations and quotas to ensure more political participation of women. Decision-makers in local government, Planners and planning bodies need to provide training on gender-sensitive practice. Capacity building among planners and decision makers is vital because what ever the gender sensitive policy adopted by the government has to be transformed in to practice by the decision makers in the local authorities, planners and planning bodies. 
When it comes to human settlement planning, it is a process which covers almost all the above mentioned steps. The question now is how we apply the said steps in human settlement planning context.

\section{Gender Analysis and Problem Identification}

Gender analysis means systematic gathering of information on different gender roles and social relations in order to understand and redress inequalities based on gender. For instance in the field of transport sector development, it required to have a clear picture of day to day lives of women in cities, their mobility patterns, domestic and family responsibilities etc. In order to do this it involves collection of disaggregated data at the house hold level. Once disaggregated data is collected, gender specific problems can be identified.

\section{Gender Needs Assessment- \& Formation of Gender Specific Objectives}

This identifies the shared and prioritized needs identified by women that arise from their common experience as a gender. The identified needs will be the gender specific objectives in a given development plan / project. According to gender development planning there are two types of gender needs have been identified: Practical Gender Needs (PGN) and Strategic Gender Needs (SGN).

According to (Moser, 1989), PGN are the immediate needs identified by women to assist their survival in their socially accepted roles, within the existing power structures. In Sri Lanka, during the last two decades, State and many NGOs have carried out many programmes to meet $\mathrm{PGN}$ such as providing adequate living conditions, health care, provision of food, access to safe water, and sanitation, and seek to ensure access to income-earning opportunities.

Strategic Gender Needs (SGN) are those needs identified by women that require strategies for challenging male dominance and privilege. These needs may relate to inequalities in the gender division of labour, in ownership and control of resources, participation in decision making, or to experiences domestic and other sexual violence. These needs are seen as to change women's status and position in society. SGN needs are difficult to achieve because higher level involvement and policy changes are required to achieve these needs.

\section{Gender based consultation and participation and identification of strategies:}

Development agencies have developed broad two approaches to find strategies to achieve gender sensitive inclusive cities. The WID (or Women In Development) approach evolved in 1970s, emphasizes the need to integrate women into the development process. It marked women should be integrated into the development process as active agents if efficient and effective development is to be achieve. Some of the suggested WID strategies are Creative income generating opportunities, improving access to credit, and to education

The other approach GAD (or Gender and Development) emerged due to the lack of progress of strategies associated with WID approach. GAD emphasizes that gender is some thing socially created and if it is socially created, it should be socially deconstructed by challenging existing gender roles and relations. To do it women should not hesitate to do jobs that are considered as male's jobs. For instance women should participate in technical professions, community organization roles, and active politics.

GAD approach focuses strategies aiming to meet both PGNs such as providing adequate living condition, health care, food provision, access to safe water, and sanitation, and seek to ensure access to income earning opportunities and SGNs such as participation in decision making and involve in non traditional gender roles.

\section{Institutionalize gender planning}

Institutional strategies basically focus on policy level changes. It means new policies have to be introduced such as reservations and quotas to ensure more political participation of women. Decision-makers in local government, Planners and planning bodies need to provide training on gender-sensitive practice. Capacity building among planners and decision makers is vital because what ever the gender sensitive policy adopted by the government has to be transformed in to practice by the decision makers in the local authorities, planners and planning bodies.

\section{Conclusion}

The role of planners is to create inclusive cities. Inclusive cities guarantee that all the people have access to economic opportunities and social physical facilities. Inclusive cities provide both economic growth and social equity and guide urban development to be not only sustainable but also humane.

It was discussed in the article that some land use characteristics may hinder the women's life styles negatively. Some of the planning issues that affect women's life styles are mono land uses practices, unplanned urban growth without paying much attention to city safety issues, lack of safety for women and children in recreational areas, women mobility is reduced by not prioritization women needs in transport planning, and burden on women due to lack of basic services in the human settlements. It was discussed the growing phenomenon of women headed families in Sri lanka and their issues in the society. It was also found out that women's participation in politics has been not at satisfactory level. 
The above conditions direct planners to reconsider the development of main land uses in cities from a women and planning perspective. It is just like planners take into account needs of other social iniquity groups such as disable, old age, and children, when prepare land use plans. Therefore development of gender planning competence on the part of all urban professionals is vital. This includes conducting an analysis of the issues and problems and formulation of strategies with a gender perspective.

\section{References}

Beall, J .1996. "Urban Governance": Why Gender Matters. in Habitat International, 19(4).

Chant, S. 1996. Gender, Urban Development and Housing. Habitat Monograph Series, UNDP: New York.

Gomez,Mario \& Gomez, Shyamala, 2001. "Preferring Gender: Gender and Politics in Sri Lanka, CIDA: Colombo.
Greed, Clara. 2000. Introducing Planning. Press, London :The Athlole.

Khan, A.H. 1991. Orangi Pilot Project Programmes. Orangi Pilot Project: Karachi.

Levy, C. 1991. "Towards Gender-Aware Provision of Urban Transport" in Gender and Third World Development: Module 5. University of Sussex: Institute of Development Studies.

Leitan, Tressie \& Gunesekara, Swinitha. 1999." Voices of Women": Responses to Political Participation: Colombo

Millennium Development Goals Country Report-Sri Lanka. 2005. National Centre for Economic Development

Weerasinghe, Rohini. 2000. Female headed households in two Villages in Sri Lanka:SIDA

Williams, Brain.2005 "Women in Cities: Gender and Urban Transport .In Habitat Debate, Vol.11 No.1 